\title{
Immunisation Status of Children Born with Orofacial Clefts Who Visited the Komfo Anokye Teaching Hospital (KATH) Multidisciplinary Cleft Clinic
}

\author{
Alexander Oti Acheampong1, Alex Ansah Owusu ${ }^{3}$, Ama Amuasi' ${ }^{1}$, Philippe Pare ${ }^{3}$, \\ Sandra Oyakhilome3 ${ }^{3}$, Baffour Gyau-Darko³, Gyikua Plange-Rhule², Peter Donkor² \\ ${ }^{1}$ Dental School, Kwame Nkrumah University of Science and Technology, Kumasi, Ghana \\ ${ }^{2}$ School of Medical Sciences, Kwame Nkrumah University of Science and Technology, Kumasi, Ghana \\ ${ }^{3}$ KomfoAnokye Teaching Hospital, Kumasi, Ghana \\ Email: aotiacheampong@yahoo.com
}

How to cite this paper: Acheampong, A.O., Owusu, A.A., Amuasi, A., Pare, P., Oyakhilome, S., Gyau-Darko, B., PlangeRhule, G. and Donkor, P. (2016) Immunisation Status of Children Born with Orofacial Clefts Who Visited the Komfo Anokye Teaching Hospital (KATH) Multidisciplinary Cleft Clinic. Open Journal of Immunology, 6, 148-153.

http://dx.doi.org/10.4236/oji.2016.64015

Received: September 20, 2016

Accepted: December 23, 2016

Published: December 26, 2016

Copyright $\odot 2016$ by authors and Scientific Research Publishing Inc. This work is licensed under the Creative Commons Attribution International License (CC BY 4.0).

http://creativecommons.org/licenses/by/4.0/ (c) $\underset{\mathrm{EY}}{\mathrm{i}}$ Open Access

\begin{abstract}
Background: The Ghana Expanded Programme on Immunisation recommends that children receive Bacillus Calmette-Guerin (BCG) and Oral Polio Vaccine (OPV) at birth; three doses of Penta vaccine and OPV at 6,10 and 14 weeks of age; and measles vaccine at 9 months of age. Aim/Objective: To evaluate the immunisation status of children born with orofacial clefts who visited the KATH multidisciplinary Cleft clinic. Methodology/Statistics: The study was a descriptive study with a cross-sectional design. The methodology consisted of in-person interviews of mothers of children born with cleft lip and palate reporting at KATH Cleft clinic. Interview guides were used for mothers who could not read. Mothers who were literate and as such could answer the questions directly were given questionnaires to fill. Result: It was reported that of the 83 children included, 47 (57\%) had been fully vaccinated and on time, 24 (29\%) had been fully vaccinated but delayed and $12(14 \%)$ had not been vaccinated at all. Children with isolated cleft palate and macrostomia were fully vaccinated on time (77.3\% and $100 \%$, respectively) as compared to those with combined cleft lip and palate (43.3\%) and isolated cleft lip (50.0\%). The majority (77\%) of the mothers who either had not vaccinated their children or had delayed in vaccinating them attributed stigmatisation as the main cause. Most of the mothers (95\%) had knowledge of immunisation. About two-thirds of the mothers (65\%) agreed that establishing an immunisation centre at the cleft clinic is the best way to improve immunisation rate among children with orofacial clefts. Conclusion: The study showed that the percentage of children with orofacial cleft who visited the KATH Cleft Clinic and were
\end{abstract}


vaccinated on time was above the national average. Cleft palates were more vaccinated and on time than cleft lips. According to the children's mothers, lack of timely vaccination was mainly due to the stigma associated with clefts in their societies.

\section{Keywords}

Cleft Lip, Cleft Palate, Combined Cleft Lip and Palate, Immunisation, Vaccination, Stigma

\section{Introduction}

Immunisation is the biological process of artificially conferring protection in a human host against infectious agents in the environment [1]. Vaccination, on the other hand, is the act or practice of inducing in a non-immune person a primary response such that on first contact with the corresponding pathogen, a rapid secondary (memory) response is mounted, leading to prevention of disease symptoms. Vaccination may lead to immunisation, and these two terms are commonly used interchangeably. Immunisation is crucial to maintaining health of the public. It is a safe, cost-effective and efficient way to prevent or ameliorate sickness and death from infectious diseases. Immunisation has led to some of the greatest public health triumphs ever, including the eradication of naturally occurring smallpox from the globe and the near eradication of polio. Children are considered fully immunised if they receive one dose of Bacillus CalmetteGuerin (BCG) and Oral Polio Vaccine (OPV) and one measles vaccine [2]. There has been a significant rise in the coverage for the six major vaccine-preventable diseases; pertussis, childhood tuberculosis, tetanus, polio, measles and diphtheria since the initiation of Expanded Programme on Immunisation in 1974 by the World Health Organisation [2] [3].

The Ghana Expanded Programme on Immunisation recommends that children receive Bacillus Calmette-Guerin (BCG) and Oral Polio Vaccine (OPV) at birth; three doses of Penta vaccine and OPV at 6,10 and 14 weeks of age; and measles vaccine at 9 months of age [4]. Immunisations are recorded on vaccine cards or booklets obtained from the clinics. Cleft lip and palate is the commonest congenital abnormalities in children. Incidence of cleft lip and palate not associated with a syndrome varies from region to region [5]. Among Japanese new-borns the incidence is 2.1 in 1000. Among Europeans the incidence is 1 in 1000 new-borns. African Americans have an incidence of 0.3 in 1000 new-borns. In Africa it is about 0.7 per 1000 live births [5].

This particular congenital abnormality is associated with social stigmatization and rejections especially in Ghana [6] [7].

The aim of this study was to assess immunisation status of children attending a multidisciplinary cleft clinic at KATH and compare with the national prevalence of Ghana. Mothers of cleft children are likely to face stigmatisation and this could affect taking their children to the weighing clinic and hence the immunisation status of these children. Failure to immunise these children puts them and their community at risk for the vaccine 
preventable diseases. It is therefore very important that research be carried out to determine the immunisation status.

\section{Methodology}

The study was a descriptive study. The study design was a cross-sectional study which adopted interviewing mothers of cleft lip and palate children reporting at KATH Cleft clinic with an interview guide. Questionnaires were used for mothers who were literate and as such could answer the questions directly. Those who could not read were assisted to understand the questions in their native language. The study choice is based on the fact that these subjects were studied at a particular point in time. Questionnaires were administered to the mothers as they waited for their turn to see the doctors at the KATH Cleft clinic. The questions comprised both closed-ended and open-ended questions. All consecutive mothers who consented to be part of the study were included in this study.

\section{Results}

The total sample size of the study was 83 . This was made up of (40) $48.2 \%$ of the children were males and (43) 51.8\% were females .Fifty-eight percent (58\%) of the children were a year and below. Most of the mothers involved in the study were aged between 21 and 30 years (52\%). Mothers aged below 21 were (5\%) and above 40 were (6\%). From this study it was found that only $4(5 \%)$ of the 83 people sampled did not have any knowledge on immunisation A total of 35\% had combined cleft lip and palate, $27 \%$ had isolated cleft palate, and $23 \%$ had isolated cleft lip, $11 \%$ bilateral cleft lip and $4 \%$ suffered from macrostomia. 56\% were either the first or the second live birth of their parents. $84 \%$ were born in a health institution. However, $59 \%$ of those born at a health institution as against $46 \%$ of those born outside such institution were immunised on time. Vaccination up to 18 months is as follows:

1) Of the 22 children due for the vaccine at 18 months during the study period, $82 \%$ had been fully vaccinated and on time.

2) $9 \%$ had been fully vaccinated but delayed.

3) $9 \%$ had not been vaccinated.

Children with isolated cleft palate and macrostomia were fully vaccinated on time (77.3\% and $100 \%$, respectively) as compared to those with combined cleft lip and palate and isolated cleft lip ( $43.3 \%$ and $50 \%$ respectively).

The study sought to ascertain why some mothers had not vaccinated their children or had delayed in vaccinating them. $77 \%$ indicated that this was due to the associated stigma.

The opinions of the mothers on how to improve the immunisation status of their children, majority (62\%) centred on establishing immunisation centre at the cleft clinic; $14 \%$ suggested home immunisation while $7 \%$ and $10 \%$ suggested establishment of special immunisation centres and more education of mothers on the need for early vaccination, respectively. 
Of the 83 participating mothers, 63 already had at least one child. When asked if they had vaccinated their other child (ren) 62 (98\%) reported to have done so. It was also reported that $20 \%$ of mothers with previous child (ren) had to change their child welfare clinic because of their child's cleft condition.

\section{Discussion}

Orofacial clefts occur more commonly in females than in males among those who report to the KATH Cleft Clinic according to this research. Children with combined cleft lip and palate (CLP) recorded the highest turn out (35\%), and isolated cleft palate was (27\%). Of the remaining $34 \%$ who presented with isolated cleft lip, $17 \%$ had left unilateral, $6 \%$ had right unilateral and $11 \%$ had bilateral cleft lip. This finding is similar to most studies from Ghana [6] [7] and Africa [8].

From this study it was found that only 4 (5\%) of the 83 people sampled did not have any knowledge on immunisation prior to this survey. This shows that a lot has been achieved in terms of education of the public on immunisation. However, the $5 \%$ though small makes it very clear that there is room for more work to be done in this regard. Studies in Nigeria show similar results [9].

In general however, this research shows that only $57 \%$ had been fully vaccinated and on time, whereas $29 \%$ had been fully vaccinated but delayed and $14 \%$ had not been vaccinated at all. Most of the $29 \%$ who were fully vaccinated but delayed were children whose cleft lips had been repaired. Their mothers explained that they sent the children for vaccination after the cleft lip had been repaired. Cleft palates were more vaccinated and on time than cleft lips. This could be due to the fact that, because isolated cleft palate does not affect the child's look, mothers of such children more readily accompany them to the weighing clinic to have them immunized. It is known that cultural beliefs have significant influence on the management of this condition [10] [11] [12] [13]. This finding is significant because empirical evidence from our community shows that parents normally hide their children with cleft from other people. Others even change their place of abode because of stigmatization and the fear of community rejection.

Very importantly, $21 \%$ of the mothers admitted to changing their settlement or weighing clinic so they could get their children vaccinated. These were mothers whose children had clefts (lips) that affected their looks and were more likely mocked by some of the members of their respective communities. One of the mothers whose child had received all the vaccinations she was due, attributed the success to the fact that she was given special services such as not joining the queue at the child welfare clinic and also the child was seen in a separate room. In all, children who had received all the vaccines they were due irrespective of whether it was on time or delayed was $86 \%$ which is greater than the general national immunisation rate of $77 \%$ as documented in the 2015 Ghana Demographic and Health Survey .

The study sought to ascertain why some mothers $(43 \%)$ had not vaccinated their children or had delayed in vaccinating them. The majority $(77 \%)$ indicated that this was due to the stigma attached to the birth of a child with cleft. The opinions of the 
mothers on how to improve the immunisation status of their children primarily centred on establishing an immunisation centre at the cleft clinic (62\%). Again 12 (14\%) suggested house to house immunisation while $7 \%$ and $10 \%$ suggested special immunisation.

\section{Conclusion}

The study showed that the percentage of children with orofacial cleft who visited the KATH Cleft Clinic and were vaccinated was above the national average. This research shows that only $57 \%$ had been fully vaccinated on time, whereas $29 \%$ had been fully vaccinated but delayed and $14 \%$ had not been vaccinated at all. Cleft palates were more vaccinated and on time than cleft lips. According to the mothers, lack of timely vaccination was mainly due to the stigma associated with clefts in their societies.

\section{Acknowledgements}

Special thanks to all mothers who attended the multidisciplinary cleft clinic at the Komfo Anokye Teaching Hospital. My heartfelt gratitude to the staff of the cleft clinic for their dedication and support during the study period.

\section{References}

[1] Elsevier (2015) Nelson Essentials of Pediatrics. 7th Edition, Marcdante \& Kliegman, 449452. https://elsevier.ca/product.jsp?isbn $=9781455759804$

[2] World Health Organisation (2008) Immunization Surveillance, Assessment and Monitoring Documents 2008. WHO. http://www.who.int/immunization/documents/monitoring/en/

[3] Koumaré, A.K., Traore, D., Haidara, F., Sissoko, F., Traoré, I., Dramé, S., et al. (2009) Evaluation of Immunization Coverage within the Expanded Program on Immunization in Kita Circle, Mali: A Cross-Sectional Survey. BMC International Health and Human Rights, 9, S13. https://doi.org/10.1186/1472-698X-9-S1-S13

[4] World Health Organisation (1 December 2013) Expanded Program of ImmunisationEPI-WHO | Regional Office for Africa.

[5] Adetayo, O., Ford, R. and Martin, M. (2012) Africa Has Unique and Urgent Barriers to Cleft Care: Lessons from Practitioners at the Pan-African Congress on Cleft Lip and Palate. The Pan African Medical Journal, 12, 15.

[6] Donkor, P., Plange-Rhule, G. and Amponsah, E.K. (2007) A Prospective Survey of Patients with Cleft Lip and Palate in Kumasi. West African Journal of Medicine, 26, 14-16. https://doi.org/10.4314/wajm.v26i1.28295

[7] Agbenorku, P., Agbenorku, M., Iddi, A., Abude, F., Sefenu, R., Matondo, P. and Schneider, W. (2011) A Study of Cleft Lip/Palate in a Community in the South East of Ghana. European Journal of Plastic Surgery, 34, 267-272. https://doi.org/10.1007/s00238-010-0513-6

[8] Kesande, T., Muwazi, L.M., Bataringaya, A. and Rwenyonyi, C.M. (2014) Prevalence, Pattern and Perceptions of Cleft Lip and Cleft Palate among Children Born in Two Hospitals in Kisoro District, Uganda. BMC Oral Health, 14, 104. https://doi.org/10.1186/1472-6831-14-104

[9] Odusanya, O.O., Alufohai, E.F., Meurice, F.P. and Ahonkhai, V.I. (2008) Determinants of Vaccination Coverage in Rural Nigeria. BMC Public Health, 8, 381.

https://doi.org/10.1186/1471-2458-8-381

[10] Olasoji, H.O., Ugboko, V.I. and Arotiba, G.T. (2007) Cultural and Religious Components in 
Nigerian Parents' Perceptions of the Aetiology of Cleft Lip and Palate: Implications for Treatment and Rehabilitation. British Journal of Oral and Maxillofacial Surgery, 45, 302305. https://doi.org/10.1016/j.bjoms.2006.09.005

[11] Johansson, B. and Ringsberg, K.C. (2004) Parents' Experiences of Having a Child with Cleft Lip and Palate. Journal of Advanced Nursing, 47, 165-173.

https://doi.org/10.1111/j.1365-2648.2004.03075.x

[12] Weatherley-White, R.C.A., Eiserman, W., Beddoe, M. and Vanderberg, R. (2005) Perceptions, Expectations, and Reactions to Cleft Lip and Palate Surgery in Native Populations: A Pilot Study in Rural India. The Cleft Palate-Craniofacial Journal, 42, 560-564.

https://doi.org/10.1597/04-003.1

[13] Mzezewa, S. and Muchemwa, F.C. (2010) Reaction to the Birth of a Child with Cleft Lip or Cleft Palate in Zimbabwe. Tropical Doctor, 40, 138-140.

https://doi.org/10.1258/td.2010.090329

Submit or recommend next manuscript to SCIRP and we will provide best service for you:

Accepting pre-submission inquiries through Email, Facebook, LinkedIn, Twitter, etc. A wide selection of journals (inclusive of 9 subjects, more than 200 journals)

Providing 24-hour high-quality service

User-friendly online submission system

Fair and swift peer-review system

Efficient typesetting and proofreading procedure

Display of the result of downloads and visits, as well as the number of cited articles

Maximum dissemination of your research work

Submit your manuscript at: http://papersubmission.scirp.org/

Or contact oji@scirp.org 